\title{
Impacts of Big Data Marketing upon Consumption Freedom and its Reflections
}

\author{
Wanting Shen \\ School of Journalism and Communication \\ Jinan University, JNU \\ Guangzhou, China \\ 312661134@qq.com
}

\author{
Han Wen \\ School of Journalism and Communication \\ Jinan University, JNU \\ Guangzhou, China \\ 342976619@qq.com
}

\begin{abstract}
Boosting of big data has brought social changes on various aspects. Big data ethics is not only about the privacy and security, but also has impacts on consumption freedom. According from the big data's impacts on consumption behavior, this paper summarized the characteristics and the marketing reforms in the era of big data. It also analyzed how big data impacts consumption freedom and gave ethical reflections of this phenomenon.

Through data collection and depicting "network portraits" of consumers, business operators plan a established consumption route for consumers with personalized prediction and accurate delivered of advertising, which imprisons the possibility of human's all-round development, weakens the people's ability of recognization. Though business operators have the positive liberty to do marketing activities, they cannot invade consumers' negative liberty, as consumers' experience is the most important element companies should consider. This paper provides a thinking framework for big data marketing ethics as well as ethical principles for promoting consumption freedom which are respect principle, participation principle and liberty principle.
\end{abstract}

Keywords-Big data; Big Data marketing; Consumption freedom; Reflection

\section{INTRODUCTION}

Big data has been subtly used in all aspects of social life, and today's society seems to have entered the big data era, which has changed people's living and working styles fundamentally or even thinking ways. [1] In terms of marketing, big data improves the scientificity of it, because through the collection for consumer data operators can get to know the demographic and geological features and through data analysis they can grasp the behaviors and mental characteristics of consumers. Based on the above, enterprises can formulate effective production plans and scientific advertisement schemes. It can be seen that big data makes accurate marketing possible, hence saving the marketing cost.

From the angle of consumers, consumption patterns have also changed. They can on one hand enjoy the product recommendations and sweet service from operators, but on the other hand subject to the disturbance of endless accurate advertisements. Their consumption freedom has been affected by big data before, in and after the purchase. Before purchase, a large amount of accurately targeted advertisements influence people's consumption decisions. Through data calculation, big data marketing can provide different advertisements to different consumers within specific time, hence turning advertisements from being artistic to being scientific. In purchase, there are endless relevant recommendations and "guess you like" guiding them to get more related commodities or supplementary ones, thus influencing the purchase process of consumers. After purchase, there are post-stage advertisement emails and short messages. With the development of big data technology, it is very easy to steal user data, hence causing privacy disclosure. The comment link at the end of e-business transaction always affects consumer freedom. [2]

\section{MARKETING REFORMS In BIG DATA ERA}

\section{A. Personalization and Interactivity}

In the big data era, everything can be digitized, including humans. Individuals that are difficult to be defined can be differentiated from others through their own large amount of data. All information-related aspects involving clothing, food, lodging and transport serve as a process of data collection. People's personal connections, ideas, preferences, purchasing power and everyday life pattern are gradually added into the huge personal information base, hence forming a threedimensional digitized "consumer". Personalized recommendations refer to the 4 recommendations of information and commodities to users according to their interest features and purchase behaviors. The recommendation methods include the most concerned information or commodities, city of customer, previous purchase behaviors and purchase records as well as possible future purchase behaviors predicted.

In the commercial sector, the feedback and interaction are very smoothly applied. Communication can also be data. The more consumers share, the more foundations for decision making. Many companies even have syntactic analysis of the Microblog of their own brand, so as to sum up the feedback comments of customers or make judgments upon the effect of marketing activities. Through the feedback of consumers against commodity consumption experience, operators can 
effectively improve product quality and service. By establishing long-term relationship with consumers, operators can develop new customers into old ones, and further expand the consuming group through the form of virtual community.

\section{B. Probability Forecasting and Accuracy}

In the book Bursts: The Hidden Pattern Behind Everything We Do, big data expert Barabsi claimed that "93\% human behaviors can be predicted”. [3] Through analysis of personal and social data, analysts find out that people's actions are regular whether they are individual or group. The problem is just that this regularity is difficult to be observed. According to accumulated data of activities, the activities of a person or group in the near future can be predicted.

In the big data era, everything can be digitalized. The more the collected specific data, the more information obtained. Data amount determines the degree of accuracy in describing targets. Therefore, marketing has become more accurate and advertisement more intelligent. Through establishing and purchasing database, operators can grasp their comprehensive information and relate it by sending a highly targeted advertisement to certain consumers. In small data era, there had been advertisement means to specific consumers like short message and email promotion; but big data can more accurately capture the traces of digital identity and use data to study consumers, so as to select the "right opportunity", "right scenario" and "right way" to send advertisements to "right targets”.

\section{IMPACTS OF BIG DATA UPON CONSUMPTION FREEDOM}

\section{A. Definition of Consumption Freedom}

Marx had clearly pointed out that "consumption is considered not only as the terminal point but also as the ending behavior of final purpose. Besides, it will in return affect starting point and re-trigger the whole process, so it does not fall into the category of economics". [4] In other words, consumption does not serve as a reason or purpose, but instead it is just a means to satisfy human development. The true purpose of consumption lies not in next consumption but in rational choices made by consumers themselves. Consumption freedom does not refer to the fact that one can purchase whatever he wants, but it turns out the decisions made based on self-demand and realization of self-development, so it is free from influence of other factors except for self-demand before, in and after purchase. Therefore, the author defines consumption freedom as the freedom of each person to engage in consuming activities for the direct purpose of self-demand instead of being intervened by the outside world as well as the freedom to consume for the fundamental purpose of promoting human development.

\section{B. Influences upon Consumption Freedom}

The first one is the rise of consumerism. The emergence of big data brings benefit to digitalization and promotes the shift of personal information to analytic data, so as to obtain more products and services. Regarding humans as pure data no doubt worsens the foreignization of humans. In the book The System of Objects, Jean Baudrillard mentioned that when the mass media favored the public, it could at the same time play a "suppressing" role through subtle means. [5] Mass media tend to utilize various means to publicize, promote and sell goods and awaken public desire to purchase the goods in absence. In short, the public most of time have no idea what they want but developers know how to constantly tap into consumption desire so as to promote the prosperity of consumerism.

The second one is the consumption privacy being violated. Privacy right refers to the right of citizens in not having their personal life illegally intervened or disclosed by others as well as the right of controlling their own information. Big data monitor consumers and their behaviors. Digitalized personal information includes consumption history (through collection of online payment), socialization relationship (through collection by social network), words and deeds records (through collection by email, mobile phone log, video surveillance) and movement traces (through GPS collection). The development of big data technology makes monitoring easier, more affordable and useful. E-business websites monitor our purchase behaviors while search engines guide our purchase directions. The social media seem to know everything, and in personal relationship network advertisement information is embedded everywhere.

The third one is the consumption path being fixed. Based on the consumers' browsing and purchasing records, big data will plan relatively fixed consumption paths and consumption matches for consumers. Big data allows internet advertisements to enter into the times of accuracy. Advertisers put on advertisements according to real-time price competition on network, so different individuals see different advertisements on different electronic devices. Seemingly, it is personalized consumption recommendations that interfere with and plan on the consumption path of each person. General direction can be seen in the consumption traces of consumers, just like gullies that seem to have distinct features but can't be erased. [6] Hence, human development becomes narrower.

\section{REFLECTIONS AND PRINCIPLES OF Big DATA MARKETING}

\section{A. Positive Freedom and Negative Freedom}

In the book Liberty, the famous British political philosopher Isaiah Berlin differentiated the two concepts of positive freedom and negative freedom. The former means the "liberty to..." while the latter means the "liberty from...". [7] His theory provides an ideal perspective for this paper in conducting analyses from the two aspects of consumers.

Firstly, operators have the positive freedom in the active sense in utilizing big data technology for improving marketing and uplifting corporate turnover, but most of the time they abuse this freedom. For example, they search for registration information of users without obtaining permission from website users; they purchase the data of potential consumers through big data technology companies; they sell the data of website users to other operators without notification or permission. Anyway, humans are interdependent, and no one's activities are completely "private" without interfering with 
others' activities. Therefore, the freedom of some people must be restrained, and the rest enjoys the freedom. Of course, ensuring the freedom of some people does not necessarily sacrifice the freedom of others. To seek solutions for human free development, we need further discussions on the concept of negative freedom and approaches. Negative freedom refers to the right of not doing something when he or she does not want. The negative freedom of consumers refers to the freedom of consumption without being intervened or forced by others. The more the scope intervened, the more the freedom. In big data marketing, negative freedom of consumers is partially deprived, which is common and obvious. No doubt, consumers can also stop "invading" marketing through blocking and report violation of privacy right. [8] For example, spam filter can automatically filter out spams, but it can't recognize that "invoice \# selling” is just a changed form of "invoice selling”, so it will not effectively filter out spams. Marketing invading privacy and daily life is deprivation of negative freedom for consumers.

\section{B. Principles of Big Data Marketing}

The principle of respect means emphasis on data and more on consumers. The principle of respect requires respect for human autonomy and independent decision making right as well as protection of users' privacy right and right to know. Enterprises shall not arbitrarily use, collect private information of users without permission. When using and collecting personal information or using it for another purpose, users must be informed. If the permission of each user can't be readily obtained, the method of "wide consent" shall be adopted according to different contexts, such as consent to the use of personal information in one type of cases instead of certain circumstances. [9] Big data serves as a powerful competition way for enterprises. We can't force enterprises to abandon it, but in doing big data marketing, the principle of respect must be put at the top by considering the degree of personalization in providing this kind of experience. Enterprises might think that their own marketing mechanism understands more about what consumers need, but this kind of understanding may not be wanted by consumers. Respecting the needs of consumers means giving them the right of making choices, namely the right to decide whether to receive big data marketing.

The principle of participation refers to public participation in making the application schemes of big data. It requires us to take measures to promote public understanding of big data and guide all stakeholders and representatives to take part in big data technology in the upper stream of decision-making concerning its $R \& D$ as well as application. Virtual data management and governance fall into an emerging area that enjoys rapid development but with a weak foundation. Apart from the dominance of government, public participation in making application schemes and management laws for big data also carries weight, because big data has a close bearing on everyone's daily life and interest. More participation will ease consumers' fear about new things and allow them to know how their own data are used. Participation process also serves as process to improve the taste matching degree of big data marketing and consumers instead of making simple judgment upon consumption behaviors through browsing records. In this way, consumers will accept the enterprise more quickly, so as to reach higher customer satisfaction degree and more significant brand involvement.

The principle of liberty refers to the emphasis on the concept of consumption freedom. Operators are supposed to know that consumption freedom constitutes an important part of consumption experience. But in front of big data convenience and efficiency, consumption freedom is likely to be neglected. In the short term, this will promote rapid increase of corporate sales volume, but long time infringement upon consumption freedom will harm the favorable impression of the consumption process, namely consumption experience, which serves as an important link of this commercial society. And ultimately this will harm the interest of all enterprises. The most promising and sustainable market is exactly the one utilizing our freedom or granting us it. Just like a low-end marketplace, complex and chaotic big data marketing environment is filled with various advertisements and thriving consumption illusions. On the other hand, a free and clean network consumption space, just like a bright and spacious high-end shopping mall, creates a free and pleasant shopping environment. [10] To build deeper brand involvement and customer loyalty, actively paying attention to and solving the problems of privacy and consumption freedom will serve as a low-cost and high-return method. Today, operators' application of big data in marketing area still plays a dominant position, so it will not be smooth to grant customers freedom. But this day will eventually arrive. Operators should bear in mind that it is more valuable to have free customers instead of bound ones.

\section{CONCLUSION}

In the era of big data, people should pay more attention to ethical problem instead of technology development. Technology is just an instrument to boost the economy, and it won't improve the happiness necessarily. Without the guidance of ethical value, the development of technology would go to the wrong direction. In the business area, except for the consideration of privacy and information security, we need to be conscious of consumption freedom, and more thinking and warning is necessary at the same time.

Consumption freedom is the freedom of doing consumption activities, which purpose is satisfies every consumer's need and desire without invasion of the outside world. Nowadays, consumer behavior is becoming more and more susceptible by big data marketing. This kind of change have caused some invasion to consumption freedom to a certain extent, because big data marketing interferences and plans too much for individual's consumption route, and therefore imprisons the possibility of human's all-rounded development.

The performances of lacking ethics are privacy and consumption freedom being invaded. Except for enacting relevant laws, there should be a ethical framing for correct ethical values. Only in this way can big data marketing develop along the "good" road and improve the efficiency. The tradeoffs of big data marketing is that operators put the consumers' experience at the first and insist the three principles: respect, participation and liberty. 


\section{REFERENCES}

[1] Kord Davis, Doug Patterson, Ethics of Big Data [M]. USA: O'Reilly Media, 2014.

[2] Zhu Junyu, Age of Big Data:Network Security and Ethical Issues[J]. New Media and Society.2014(4). (In Chinese)

[3] Barabási A L, Bursts: the hidden patterns behind everything we do, from your e-mail to bloody crusades[M]. Penguin, 2010.

[4] Selections of K. Marx and F. Engels. Vol. 2[M]. Beijing:People's Publishing House, 1972.

[5] Baudrillard. The System of Objects [M]. Times culture publishing company, 1997.
[6] Mayer-Schönberger V, Cukier K, Big data: A revolution that will transform how we live, work, and think[M]. Houghton Mifflin Harcourt, 2013.

[7] Berlin I. Liberty[J]. 2002.

[8] David Brooks, What Data Cannot Do [N] .The NewYork Times,2013.

[9] Qiu Renzong, Huang Wen, Zhai Xiaomei, Ethical Issues in Big Data Technology[J]. Science and Society,2014,4(1). (In Chinese)

[10] Mayer-Schönberger V, Delete: the virtue of forgetting in the digital age[M]. Princeton University Press, 2011. 